\title{
FABRICAÇÃO DE SUPERFÍCIE SUPERHIDROFÓBICA POR MÉTODO DE DEPOSIÇÃO DE COBRE
}

\author{
G. B. MARTINEZ 1 , F. G. E. NOGUEIRA ${ }^{2}$, T. F. PADUA ${ }^{2}$ \\ ${ }^{1}$ Universidade Federal de São Carlos, Departamento de Física \\ ${ }^{2}$ Universidade Federal de São Carlos, Departamento de Engenharia Química \\ E-mail para contato: giovanni.briscese@df.ufscar.br
}

\begin{abstract}
RESUMO - Superfície superhidrofóbicas são importantes devido às suas inúmeras aplicações, que chamam muito atenção tanto da comunidade acadêmica quanto da indústria. O objetivo deste trabalho foi analisar a eficácia ao se construir uma superfície utilizando o método de deposição galvânica sem eletricidade. Os experimentos foram realizados mergulhando uma placa de aço dentro de uma solução de sulfato de cobre para que o aço fosse recoberto com o cobre. Após o cobrimento, foi realizada passivação com solução alcoólica de ácido esteárico. A superfície produzida apresentou regiões superhidrofóbicas e outras somente hidrofóbicas, sendo algumas regiões com ângulo de contato de $140,33^{\circ}$ (hidrofóbicas) e outras com ângulo de contato de 162,2 (superhidrofóbicas).
\end{abstract}

\section{INTRODUÇÃO}

O trabalho de Xu et al., (2009) destaca que podemos encontrar organismos vivos que apresentam propriedades de superhidrofobia na natureza, como a flor de lótus, que tem a sua superfície totalmente rugosa, na qual são formadas cavidades ocupadas pelo ar atmosférico, não deixando as gotículas de água penetrarem na flor. Inspirados na natureza, diversos autores (Xu et al., 2009; Guo et al., 2012 a, b; Xue et al., 2010; Park e Hwang, 2016; Ou et al., 2015; Yuan et al., 2016;) propuseram diferentes métodos para o desenvolvimento de superfícies superhidrofóbicas artificiais. Para que a superfície seja considerada superhidrofóbica, ela deve possuir um ângulo de contato maior que $150^{\circ}$ (Figura 1), e ângulo de deslizamento menor que $10^{\circ}$. Os trabalhos de Xue et al. (2010), Guo et al. (2012 a, b), Xu et al. (2009) e Park e Hwang (2016) mostraram que estas superfícies estão chamando muito atenção tanto da comunidade acadêmica quanto da indústria por suas aplicações práticas, como: autolimpeza, anticorrosão, anticongelamento, separação de óleo e água e redução do atrito.

Figura 1 - Ângulo de contato de um líquido com um sólido

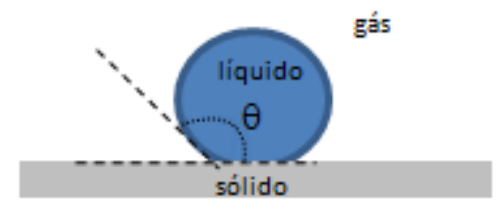


Alguns métodos como processo sol-gel, gravação em laser e plasma, gravação química, montagem coloidal e deposição galvânica são alternativas para a fabricação de uma superfície superhidrofóbica. Entretanto, a utilização da maioria desses métodos necessita de muitos gastos e equipamentos específicos para a realização. A deposição galvânica espontânea possui bom custo-benefício e é apropriada para construção de superfícies de grande área, segundo (Xu et al., 2009; Guo et al., 2012 a, b; Ou et al., 2015; Yuan et al., 2016;). Geralmente, os métodos de deposição em metais para obtenção de superhidrofobia envolvem duas etapas. A primeira consiste em recobrir substrato metálico com uma camada texturizada de outro metal. Depois desta etapa, é feita a modificação da superfície hidrofílica do metal com uma substância hidrofóbica. Por exemplo, é comum a aplicação de solução ácida (como o ácido esteárico), fazendo com que a peça seja revestida por uma película de baixa energia superficial. A combinação da morfologia adequada e a química da superfície confere a superhidrofobia ao material.

O método utilizado para o desenvolvimento deste trabalho tem como ponto de partida os trabalhos de Liu et al. (2012); Guo et al. (2012a) e Guo et al. (2012 b); que obtiveram superfícies superhidrofóbicas em materiais metálicos. O objetivo do trabalho é testar o recobrimento com cobre proposto por Guo et al. (2012 a) para a nanoestruturação. Porém, trocando o PTES da segunda etapa $\left(\mathrm{CF}_{3}\left(\mathrm{CF}_{2}\right)_{7} \mathrm{CH}_{2} \mathrm{CH}_{2} \mathrm{Si}\left(\mathrm{OCH}_{3}\right)_{3}\right)$ por ácido esteárico, visto que o ácido esteárico é um reagente mais barato e foi utilizado por Guo et al. (2012 b) após recobrimento com prata.

\section{DETALHES EXPERIMENTAIS}

\subsection{Materiais}

Placa de aço 1045 de dimensões 3 x 1,7 cm, balança de precisão (4 algarismos significativos), dessecador, bomba de vácuo, suporte universal, Béqueres de $25 \mathrm{~mL}$ e $500 \mathrm{~mL}$, balões volumétricos $(25 \mathrm{~mL})$, sulfato de cobre hexahidratado, ácido esteárico, agitador magnético, álcool (etanol) absoluto e água destilada.

\subsection{Métodos para a fabricação da superfície}

Primeiro, a peça que estava polida manualmente foi lavada com água destilada e foi submetida ao polimento utilizando lixadeira orbital (metalografia). Após este método foi utilizado água destilada para a lavagem da peça. Com a amostra limpa, esta foi imersa em 0,046M de uma solução de sulfato de cobre hexahidratado com água destilada. Após reagir por seis minutos, a peça foi retirada e fez-se a lavagem desta com água destilada, seguido pela secagem utilizando um pano de alta absorção.

Para revestir uma película de baixa energia superficial, a amostra foi imersa em 0,030M de uma solução alcoólica (etanol) de ácido esteárico por $24 \mathrm{~h}$. Finalmente, a peça foi retirada da imersão, e esta foi lavada com álcool (etanol) absoluto e secada utilizando um pano de alta absorção. 


\subsection{Métodos de Caracterização}

Análise da Morfologia e Superfície: Foi utilizado um microscópio ótico (MO) Olympus BX41M-LED com aumento de 100x e câmera de captura Infinity 1 para observar e capturar imagens da superfície da peça após polimento.

A análise morfológica dos materiais nanoestruturados foi obtida por microscopia eletrônica de varredura (MEV) utilizando um equipamento Philips XL-30 FEG operando com feixe de elétrons de $15 \mathrm{kV}$.

Medida do ângulo de contato: Utilizou-se um Microgoniômetro CAM200 (grupo de pesquisa em polímeros prof. Bernhard Gross) para a medida do ângulo de contato da água (método da gota séssil) no substrato e assim definir a eficácia do método para construção de superfície. Neste método, uma gota de volume conhecido foi fotografada em repouso sobre o substrato e o ângulo foi estimado por análise da imagem.

\section{RESULTADOS E DISCUSSÕES}

Feito o polimento, foi feita a análise da morfologia da peça utilizando um microscópio ótico, sendo obtida algumas imagens da superfície, conforme mostra a figura 2. Após a retirada da peça do banho de cobre, foi possível observar visualmente que a peça havia sido totalmente coberta pelo cobre, conforme mostra a figura 3-a.

Figura 2 - Morfologia da peça de diferentes regiões.

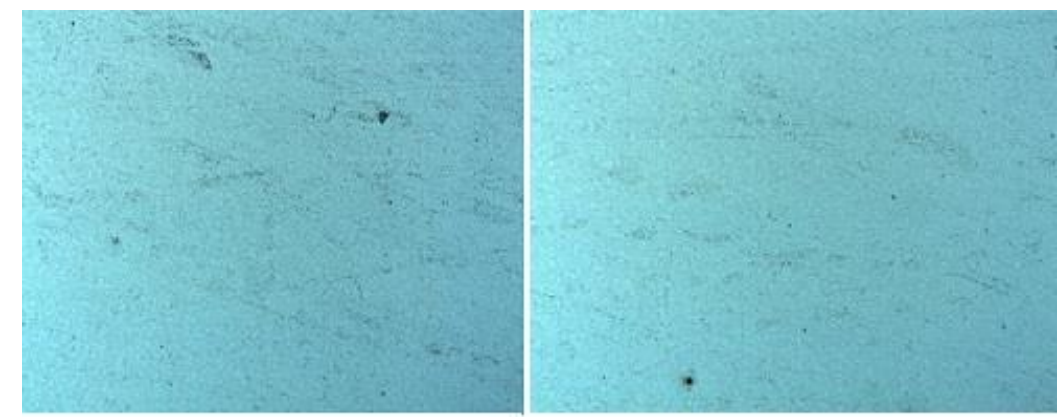

Amostras não polidas ou que receberam banho de cobre de até três minutos, apresentaram resultados insatisfatórios quanto ao recobrimento de cobre. Após a imersão em solução alcoólica de ácido esteárico, foi obtida uma placa com a presença de regiões esbranquiçadas, conforme mostra a figura 3-b.

O ângulo de contato indicou que algumas regiões da placa não atingiram o ângulo desejado (mínimo de $150^{\circ}$ ). Assim, mediu-se os ângulos nas regiões central, centro-baixo, centro-cima e lateral, conforme mostra a figura 4. Para a análise dos resultados foi utilizada uma gota de $5 \mu \mathrm{L}$ nas regiões mencionadas e os resultados estão apresentados na Tabela 1. 
Figura 3 - a) Cobertura da peça após a imersão na solução de sulfato de cobre. b) Placa após a imersão em solução alcoólica de ácido esteárico.

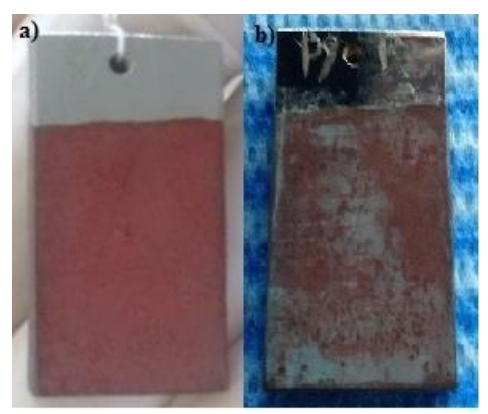

Figura 4 - Regiões da placa: 1 - Lateral, 2 - Centro-cima, 3 - Central, 4 - Centro-baixo.

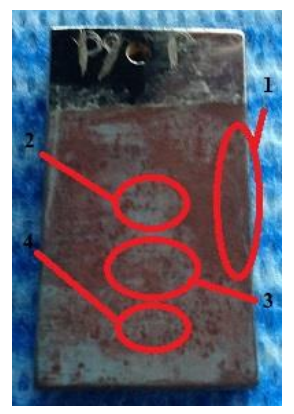

Tabela 1 - Tabela de dados da gota em contato com a placa feita pelo goniômetro.

\begin{tabular}{|c|c|c|c|}
\hline Região & $\begin{array}{c}\text { Ângulo de contato à } \\
\text { esquerda (graus) }\end{array}$ & $\begin{array}{c}\text { Angulo de contato à } \\
\text { direita (graus) }\end{array}$ & $\begin{array}{c}\text { Média do ângulo de } \\
\text { contato (graus) }\end{array}$ \\
\hline Lateral & 140,33 & 140,90 & 140,61 \\
\hline Central & 159,93 & 159,96 & 159,94 \\
\hline $\begin{array}{c}\text { Centro- } \\
\text { baixo }\end{array}$ & 150,49 & 150,54 & 150,52 \\
\hline $\begin{array}{c}\text { Centro- } \\
\text { cima }\end{array}$ & 158,09 & 162,20 & 160,15 \\
\hline
\end{tabular}

A tabela indica ângulos superiores a $150^{\circ}$ (áreas superhidrofóbicas) e a placa foi considerada apenas hidrofóbica (ângulos superiores a $90^{\circ}$ ) em outras regiões. Pelo goniômetro, foi possível o registro de algumas das imagens das regiões citadas anteriormente, conforme mostra a figura 5.

Visualmente, conforme mostrado na figura 5, é possível notar a diferença dos ângulos de contato entre as diferentes regiões como apresentado na tabela 1, sendo os melhores resultados pertencentes às áreas esbranquiçadas da placa. Provavelmente, estas regiões foram 
as que obtiveram maior funcionalização com o ácido, já que o aparecimento de regiões mais claras ocorria somente depois do tratamento com a substância.

Alguns trabalhos da literatura utilizaram técnica similar em que foi possível fabricar uma superfície superhidrofóbica e o ácido esteárico apresentou potencial para funcionalização da superfície, já que algumas regiões apresentaram as propriedades desejadas.

Para traçar as razões de diferença entre as regiões neste trabalho, foi utilizado um microscópio eletrônico de varredura (MEV) para observar a morfologia da amostra, sendo que a estrutura observada é do tipo flor de lótus, conforme mostra a figura 6. Esta era a morfologia desejada e que foi reportada na literatura a partir do recobrimento de cobre em condições similares.

Deste modo, a estruturação da superfície foi adequada e algumas hipóteses foram levantadas sobre as razões de porque a peça inteira não apresentou o comportamento desejado: impurezas no corpo de prova e a concentração de ácido esteárico. O corpo de prova foi obtido a partir do recorte de uma placa metálica, onde se retirou a borda da placa, região aonde pode ocorrer concentração de impurezas.

Figura 5 - Gotículas de $5 \mu \mathrm{L}$ observadas pelo Goniômetro. a) Região Centro-baixo b) Região Central. c) Região lateral.

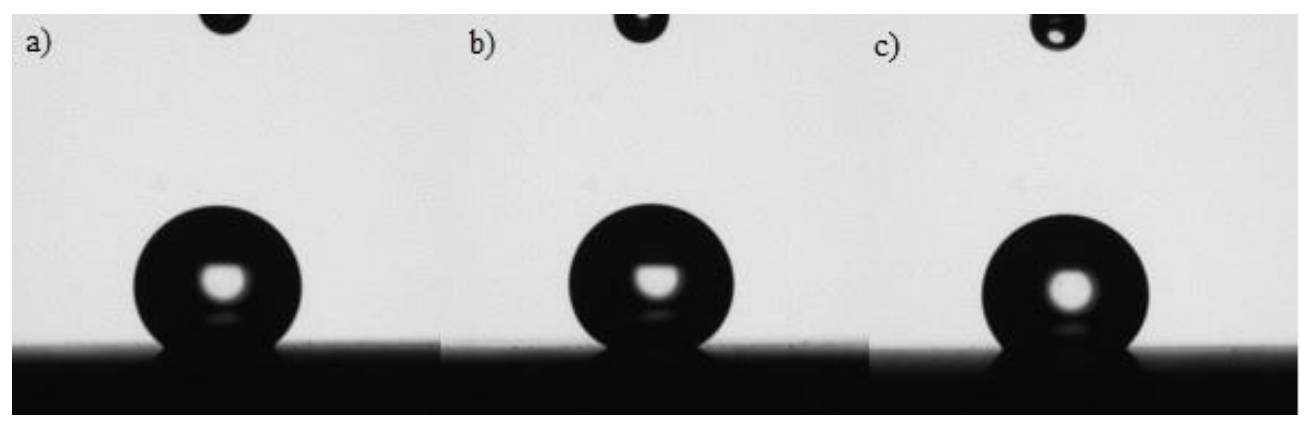

Figura 6 - Imagem da estrutura de uma amostra feita por um MEV.

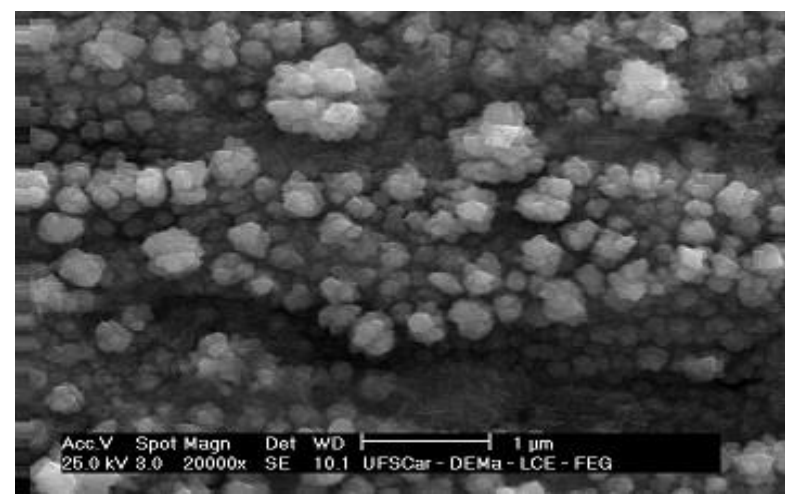

\section{CONCLUSÕES}

O ácido esteárico apresentou potencial para desenvolvimento do processo de funcionalização da superfície. Porém, o objetivo da fabricação de uma superfície superhidrofóbica foi atingido 
parcialmente, sendo que não foi alcançado a superhidrofobia em todas as regiões da placa. Pôde-se perceber também que as regiões que melhor se comportaram como superhidrofóbicas foram àquelas esbranquiçadas da placa, provavelmente devido à presença do ácido esteárico na superfície.

Em vista das hipóteses levantadas para que a superhidrofobia não tenha ocorrido em todo o substrato, ensaios futuros avaliarão os efeitos da concentração de ácido esteárico, tempo de exposição à solução de sulfato de cobre e utilizarão corpos de prova obtidos do centro de barras metálicas recortadas, de modo a evitar os efeitos das impurezas no processo.

\section{REFERÊNCIAS}

GUO, F.; SU, X.; HOU, G.; LI, P. Bioinspired fabrication of stable and robust superhydrophobic steel surface with hierarchical flowerlike structure. Colloids and Surfaces A: Physicochem. Eng. Aspects, v. 401, p. 61-67, 2012 a.

GUO, F.; SU, X.; HOU, G.; LI, P. Superhydrophobic silver surface with dendrites structure on steel substrate by a facile elecrtoless galvanic deposition process. Applied Surface Sci., v. 258, p. 4906-4910, 2012 b.

LIU, X.; SONG, J.; WU, L.; XU, W.; LU, Y.; SUN, J. Fabrication of superhydrophobic surfaces with high adhesive forces towards water on steel substrates. Micro Nano Lett., v. 7, p. 456-459, 2012.

OU, J.; SHI, Q.; CHEN, Y.; WANG, F.; XUE M.; LI, W. Superhydrophobic surfaces on diverse metals based on ultrafast sequential deposition of silver and stearic acid. Applied Surface Sci., v. 326, p. 139-144, 2015.

PARK, B.; HWANG. W. A facile fabrication method for corrosion-resistant micro/nanostructures on stainless steel surfaces with tunable wettability. Scripta Materialia, v. 113, p. 118-121, 2016.

XU, X.; ZHANG, Z.; YANG, J. Fabrication of Biomimetic Superhydrophobic Surface on Engineering Material by a Simple Electroless Galvanic Deposition Method. Langmuir, v. 26 (5), p. 3654-3658, 2010

XUE, CHAO-HUA; JIA, SHUN-TIAN; ZHANG, J.; MA, JIAN-ZHONG. Large-area fabrication of superhydrophobic surfaces for practical applications: an overview. Sci. Technol. Adv. Mater., v. 11 (033002), 2010.

YUAN, C.; HUANG, M.; YU, X.; MA, Y.; LUO, X. A simple approach to fabricate the rose petal-like hierarchical surfaces for doplet transportation. Applied Surface Sci., v. 385, p. 562-568, 2016.

\section{AGRADECIMENTOS}

Os autores agradecem ao DEMA (Departamento de Engenharia de Materiais) da UFSCar pelo laboratório de metalografia e ao Grupo de pesquisa em polímeros prof. Bernhard Gross do instituto de física da USP - São Carlos. 